Contract No. and Disclaimer:

This manuscript has been authored by Savannah River Nuclear Solutions, LLC under Contract No. DE-AC09-08SR22470 with the U.S. Department of Energy. The United States Government retains and the publisher, by accepting this article for publication, acknowledges that the United States Government retains a non-exclusive, paid-up, irrevocable, worldwide license to publish or reproduce the published form of this work, or allow others to do so, for United States Government purposes. 


\title{
ANALYSIS OF THE RATE OF ADSORPTION OF MOISTURE ONTO PLUTONIUM OXIDE POWDERS
}

\author{
James E. Laurinat \\ Savannah River National Laboratory \\ Savannah River Site, Aiken, SC 29808 \\ Email: james.laurinat@srnl.doe.gov
}

\author{
Matthew R. Kesterson \\ Savannah River National Laboratory \\ Savannah River Site, Aiken, SC 29808 \\ Email: matthew.kesterson@srnl.doe.gov
}

\author{
Steve J. Hensel \\ Savannah River Nuclear Solutions \\ Savannah River Site, Aiken, SC 29808 \\ Email: steve.hensel@srnl.doe.gov
}

\begin{abstract}
Rates of adsorption of moisture onto plutonium oxide powders exposed to air are modeled. The moisture contents of these powders must be limited to minimize the radiolytic generation of flammable hydrogen gas when the plutonium oxide subsequently is stored in containment vessels. The pressure in the vessels is related to the amount of moisture adsorbed. Moisture adsorption rates are modeled for powders in two different containers used by the Savannah River Site (SRS) HB-Line facility, a B vial and a product can. The adsorption models examine the effects of the powder layer fill height, gas mixing conditions above the powder layer, and ambient relative humidity. Moisture distribution profiles are calculated to enable the evaluation of the effect of sampling location on the measured moisture content. The adsorption models are applied using the COMSOL Multiphysics ${ }^{\circledR}$ finite element code. The $\mathrm{COMSOL}^{\circledR}$ models couple moisture diffusion with thermal conduction and radiation. The models incorporate an equilibrium adsorption isotherm and a detailed model for combined radiation and conduction heat transfer in the powder, both developed at Los Alamos National Laboratory. The COMSOL ${ }^{\circledR}$ adsorption rate calculations are successfully benchmarked using an analytical, one-dimensional ash and pore diffusion model.
\end{abstract}

\footnotetext{
${ }^{\circledR}$ COMSOL Multiphysics is a registered tradename of COMSOL, Inc., of Burlingame, Massachusetts.
}

\section{INTRODUCTION}

Plutonium oxide powders can adsorb significant amounts of moisture when they are exposed to the atmosphere. Subsequent radiolysis of these powders inside closed containment vessels can generate flammable mixtures of hydrogen gas and air. The pressure in these vessels is related to the amount of moisture adsorbed. A mass transfer model is developed to predict the rate at which moisture is adsorbed and the moisture concentration distribution within the oxide layer. The concentration profile will be used to determine sampling locations required to obtain a representative average moisture concentration. Adsorption rates are analyzed for two containers used at the SRS HB-Line facility, a B vial used for product samples with a capacity of $8.25 \mathrm{E}-06 \mathrm{~m}^{3}$ and a product can with a capacity of $8.66 \mathrm{E}-04 \mathrm{~m}^{3}$. Analysis parameters include powder layer fill height, gas mixing conditions above the powder layer, and ambient relative humidity.

The adsorption rate calculations assume that an initial, chemisorbed molecular layer is already present on the surface of the oxide and that, therefore, any adsorption that takes place is physisorption. The number of layers of chemisorbed layers is not known. Consequently, a conservative assumption is made that the oxide layer does not contain any moisture at the beginning of the exposure period. This assumption is conservative in that it maximizes the amount of additional moisture that is adsorbed before the oxide surface becomes saturated.

Adsorption rates are benchmarked with the results of moisture adsorption tests conducted by Los Alamos National

The United States Government retains, and by accepting the article for publication, the publisher acknowledges that the Unites States Government retains, a non-exclusive, paid-up, irrevocable worldwide license to publish or reproduce the published form of this work, or allow others to do so, for United States Government purposes. This work was prepared under Federal Contract DE-AC09-08SR22470. 
SRNL-STI-2013-00649

Laboratory (LANL). Initial rates are benchmarked using data from Berg et al. adsorption measurements for humidified helium. ${ }^{1}$ Diffusion-limited rates are benchmarked with the results of Haschke and Ricketts adsorption tests for oxide calcined at $973 \mathrm{~K}\left(700{ }^{\circ} \mathrm{C}\right)$ and then exposed to air with $1 \%$ relative humidity., ${ }^{2,3}$ The Haschke and Ricketts tests are benchmarked with both a one-dimensional analytical reactiondiffusion model and an axisymmetric two-dimensional finite element model, using the COMSOL ${ }^{\circledR}$ code. Equilibrium moisture adsorption levels are correlated as a function of the relative humidity, temperature, and oxide specific surface area, using adsorption isotherms reported by Veirs, Berg, and Crowder. $^{4}$

\section{NOMENCLATURE}

$\mathrm{A}_{\mathrm{H}_{2} \mathrm{O}}$ surface area occupied by one water molecule, $\mathrm{m}^{2}$

C adsorption isotherm constant

$\mathrm{C}_{0} \quad$ adsorption isotherm constant at reference temperature

$\mathrm{d}_{\mathrm{i}} \quad$ inner diameter of container, $\mathrm{m}$

D molecular diffusivity of water vapor in air, $\mathrm{m}^{2} / \mathrm{s}$

$\mathrm{D}_{\text {eff }} \quad$ effective diffusivity for water vapor, $\mathrm{m}^{2} / \mathrm{h}$

$\Delta \mathrm{H}_{\mathrm{ad}} \quad$ heat of adsorption in excess of heat of condensation, $\mathrm{J} / \mathrm{mole}$

$\mathrm{k}_{\mathrm{a}} \quad$ intrinsic (chemical) adsorption rate, $\mathrm{mol} / \mathrm{m}^{2} / \mathrm{h}$

$\mathrm{k}_{\mathrm{g}}$ gas thermal conductivity, $\mathrm{W} / \mathrm{m} / \mathrm{K}$

L depth of oxide layer where diffusion controls rate of adsorption, $\mathrm{m}$

$\mathrm{L}_{\mathrm{p}} \quad$ penetration depth for recirculating flow in gas space above oxide layer, $\mathrm{m}$

$\mathrm{m}_{\mathrm{H}_{2} \mathrm{O}}$ adsorbed moisture content at saturation, wt \%

$\mathrm{M}_{\mathrm{H}_{2} \mathrm{O}}$ molecular weight of water, $18 \mathrm{~g} / \mathrm{mole}$

$\mathrm{n}_{\mathrm{m}} \quad$ number of monolayers of adsorbed moisture

$\mathrm{N}_{\mathrm{A}} \quad$ Avogadro's number, 6.022E23 molecules/mole

$\mathrm{N}_{\mathrm{s}} \quad$ surface adsorption density for moisture at saturation, $\mathrm{mol} / \mathrm{m}^{2}$

$\mathrm{R}$ relative humidity

$\mathrm{R}^{\prime} \quad$ relative humidity gradient, $1 / \mathrm{m}$

$\mathrm{R}_{\mathrm{g}} \quad$ ideal gas law constant, $82.057 \mathrm{~cm}^{3}$ atm/mole/K or 8.314 J/mole/K

$\mathrm{R}_{0} \quad$ relative humidity at the oxide layer surface, assumed to be equal to the ambient air relative humidity

$\mathrm{s}_{\mathrm{BET}} \quad$ BET specific surface area, $\mathrm{m}^{2} / \mathrm{g}$

$\mathrm{t}$ exposure time, $\mathrm{h}$

$\mathrm{T}$ temperature, $\mathrm{K}$

$\mathrm{T}_{0} \quad$ reference temperature for adsorption isotherm constant, $296.15 \mathrm{~K}$

$\mathrm{v}_{\mathrm{m}} \quad$ specific surface area of oxide, $\mathrm{m}^{2} / \mathrm{g}$

$\mathrm{w}_{\mathrm{H}_{2} \mathrm{O}}$ adsorbed moisture content in one monolayer of adsorbed moisture, wt \%

$\mathrm{x} \quad$ distance from surface of oxide, $\mathrm{m}$

$\mathrm{y} \quad$ dimensionless depth of oxide saturated with adsorbed moisture

$\varepsilon \quad$ porosity of oxide

$\theta$ dimensionless exposure time

$\rho_{\mathrm{g}, \mathrm{H}_{2} \mathrm{O}}$ density of water vapor at saturation, $\mathrm{g} / \mathrm{m}^{3}$

$\rho_{\mathrm{H}_{2} \mathrm{O}} \quad$ liquid water density, $1.0 \mathrm{~g} / \mathrm{m}^{3}$

$\rho_{\text {ox }} \quad$ pycnometric density of oxide, $\mathrm{g} / \mathrm{m}^{3}$

$\tau \quad$ tortuosity

$\nabla^{2} \quad$ Laplacian operator for diffusion

MODEL FOR GAS MIXING ABOVE THE OXIDE LAYER

Mass transfer through the gas space inside the container limits the rate of adsorption of moisture in the oxide, so a review of this mass transfer is a good place to begin to describe the adsorption model. The transfer of water vapor through the gas layer above the oxide powder is modeled as molecular diffusion. Preliminary calculations showed that the Rayleigh numbers for the $\mathrm{B}$ vial and the product can are less than the critical value of 1708 required for the onset of natural convection. $^{5}$ Consequently, mass transfer occurs solely by molecular diffusion in the gas space above the oxide layer, provided that recirculating flow around either the vial or the product can does not displace any gas from that space.

The amount of displacement of gas from an open container is estimated from measurements of "driven cavity" flow, in which a gas stream is blown across an open gap in a flat surface. The gas velocity across the top of the container is expected to be low, and the vial diameter is small, so the gas flow across the vial top is expected to be in the laminar range. In such laminar flows, some of the flow across the top of the gap is driven into the gap. The recirculating flow in the top portion of the gap (i.e., the primary recirculation cell) is accompanied by a secondary cell of recirculating gas in the bottom portion of the gap, as shown by Fig. 1. The velocities for this secondary cell typically are quite low, so that the gas may be considered to be quiescent and so that any mass transfer may be assumed to occur by diffusion.

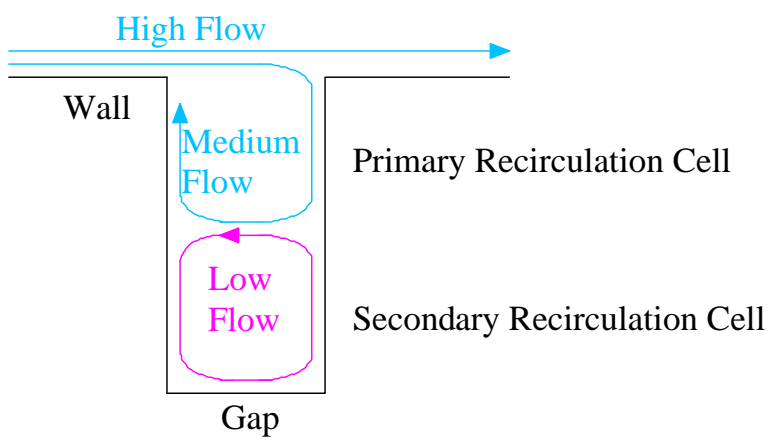

FIG. 1 RECIRCULATING "DRIVEN CAVITY" FLOW 
Measurements of laminar flows across a sinusoidal depression demonstrated that the depth of the primary recirculation cell approaches a constant fraction of the total gap width, independent of the depth of the depression. ${ }^{6}$ Another set of laminar flow measurements showed that the limiting depth of the primary recirculation cell for a square-edged gap is approximately equal to the gap width. ${ }^{7}$ The equivalent depth for flow across an open container is approximated as being equal to the average gap across the top of the vial, which is given by

$$
\mathrm{L}_{\mathrm{p}}=\frac{\pi \mathrm{d}_{\mathrm{i}}}{4}
$$

The equivalent penetration depth for the $B$ vial is calculated to be $0.0137 \mathrm{~m}$. It is inferred that the gas in the B vial mixes with the ambient air above this depth and that virtually all water vapor transfer below this layer is due to molecular diffusion. Accordingly, the top surface of the B vial is lowered to a depth $0.0137 \mathrm{~m}$ below the actual height in the adsorption model. To evaluate the effect of the gas space depth on the rate of adsorption, separate calculations also are performed using the actual B vial height and with mixing down to the surface of the oxide layer.

A similar parametric analysis is conducted to evaluate the effect of gas mixing on moisture adsorption in the product can. The mixing depth for the product can is $0.0651 \mathrm{~m}$.

\section{MOISTURE ADSORPTION RATE MODELING}

Two approaches are employed to calculate the rate of moisture adsorption by the oxide layer, a fundamental approach that combines a reaction rate for adsorption with a model for diffusion of water vapor in the oxide powder and an analytical approximation that couples ash layer and pore diffusion models. The fundamental approach is used to set up a COMSOL Multiphysics ${ }^{\circledR}$ finite element model for the adsorption process. The analytical model is included to serve as a check on the finite element calculations and to provide insight on the effects of model parameters.

\section{COMSOL ${ }^{\circledR}$ FINITE ELEMENT MODEL}

Preliminary calculations demonstrated that the thermal mass of the B vial was sufficient to keep the gas and the oxide inside the vial at a nearly uniform temperature (within $\pm 1{ }^{\circ} \mathrm{C}$ ). Therefore, the thermal analysis was dropped from the COMSOL $^{\circledR} \mathrm{B}$ vial model, leaving only the mass transfer equations. Moisture adsorption creates significant temperature gradients in the product can due to its larger size. These temperature gradients were modeled using an effective thermal conductivity correlation for plutonium dioxide powder developed by Bielenberg et al. ${ }^{8}$ Because the primary focus of this study is mass transfer and adsorption, details of the Bielenberg et al. correlation and the heat transfer model are not provided.
The low concentrations of water vapor in the gas and the small particle size of the plutonium oxide powder rule out natural convection in the oxide layer. Consequently, the oxide layer mass transfer equations include only accumulation, diffusion, and reaction terms. The mass balance applied to the gas phase inside the oxide powder takes the form

$$
\varepsilon \rho_{\mathrm{g}, \mathrm{H}_{2} \mathrm{O}} \frac{\partial \mathrm{R}}{\partial \mathrm{t}}=\rho_{\mathrm{g}, \mathrm{H}_{2} \mathrm{O}} \mathrm{D}_{\text {eff }} \nabla^{2} \mathrm{R}-\mathrm{k}_{\mathrm{a}} \mathrm{M}_{\mathrm{H}_{2} \mathrm{O}}(1-\varepsilon) \rho_{\mathrm{ox}} \mathrm{v}_{\mathrm{m}}
$$

The water vapor density at saturation is calculated from the ideal gas law, based on the partial pressure of the water vapor, where the water vapor pressure is given by an Antoine formula. ${ }^{9}$

The effective diffusivity is calculated as the molecular diffusivity, multiplied by the porosity of the powder and divided by the tortuosity:

$$
\mathrm{D}_{\text {eff }}=\frac{\mathrm{D} \varepsilon}{\tau}
$$

The molecular diffusivity is calculated using the Fuller, Schettler, and Giddings correlation. ${ }^{10}$ The tortuosity represents the relative increase in the average path length for diffusion around the particles in the oxide powder. The tortuosity factor is varied to fit the benchmarking data, as explained later.

It may be noted that the intrinsic adsorption rate is independent of the relative humidity. This assumption is based on the measurements of Berg et al., ${ }^{2}$ as discussed.

The mass balance applied to the gas phase above the oxide layer is the transient diffusion equation, without the reaction term:

$$
\rho_{\mathrm{g}, \mathrm{H}_{2} \mathrm{O}} \frac{\partial \mathrm{R}}{\partial \mathrm{t}}=\rho_{\mathrm{g}, \mathrm{H}_{2} \mathrm{O}} \mathrm{D} \nabla^{2} \mathrm{R}
$$

The mass balance for moisture adsorbed onto the solid is

$$
0.01(1-\varepsilon) \rho_{o x} \frac{\mathrm{dm}_{\mathrm{H}_{2} \mathrm{O}}}{\mathrm{dt}}=\mathrm{k}_{\mathrm{a}} \mathrm{M}_{\mathrm{H}_{2} \mathrm{O}}(1-\varepsilon) \rho_{\mathrm{ox}} \mathrm{v}_{\mathrm{m}}
$$

The factor 0.01 converts $\mathrm{m}_{\mathrm{H}_{2} \mathrm{O}}$ from a mass percentage to a mass fraction.

The COMSOL Multiphysics ${ }^{\circledR}$ model is discretized in cylindrical axisymmetric coordinates. Fig. 2 depicts the components of the $\mathrm{B}$ vial model; a similar model was constructed for the product can. There are approximately 54,000 elements in the finite element mesh for the B vial, of which over 40,000 are in the oxide layer. This mesh for the product can contains approximately 12,000 elements. 


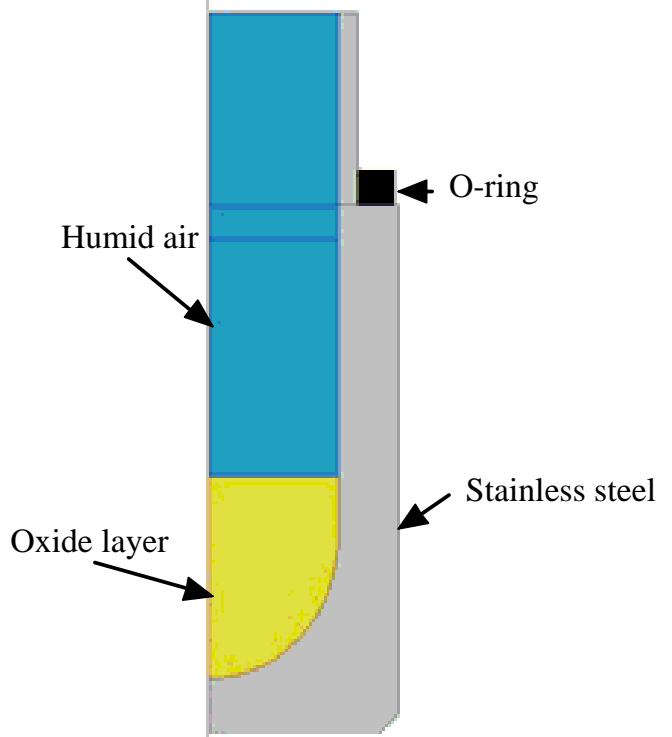

FIG. 2 COMSOL ${ }^{\circledR}$ DOMAIN

The adsorption model was implemented within COMSOL Multiphysics ${ }^{\circledR}$ using the Species Transport in Porous Media Module. This module contains the required mass balance and adsorption reaction terms.

\section{ANALYTICAL, ONE-DIMENSIONAL MOISTURE ADSORPTION MODEL}

The rate of adsorption can be estimated by combining a pore diffusion model with an ash layer diffusion model. The combined model assumes that there is a thin layer inside the oxide powder where the rate of adsorption depends on both an intrinsic chemical adsorption rate and the rate of diffusion of water vapor to the reacting surface. It is assumed that this thin layer is covered by an "ash layer" where the adsorption rate depends only on the rate of diffusion. The rate of moisture adsorption is estimated as the rate of growth of this ash layer, multiplied by the density of the adsorbed moisture at saturation.

Both the ash layer model and the pore diffusion model have been developed previously. The ash layer model was developed to describe partial combustion in porous particles, with the formation of an incombustible ash through which air or oxygen must diffuse to reach the burning front. ${ }^{11}$ This model also applies to powder beds. The pore diffusion model originally was used to describe diffusion and reaction in catalyst pellets, ${ }^{12}$ but also can be construed to be applicable to powder beds. Typically, in catalyst pellets or ion exchange beads, the pore diffusivity can be orders of magnitude smaller than ordinary molecular diffusivity. In this analysis, pore diffusion differs from ash layer diffusion in that it models mass transfer both across and along the reacting front in the active region of the oxide bed where adsorption takes place, whereas ash layer diffusion occurs in the portion of the bed where the oxide is already saturated with adsorbed moisture. Because pore diffusion takes place in two directions, transverse and parallel to the adsorption front, and ash layer diffusion occurs in one direction, transverse to the front, the tortuosity for the pore diffusivity is expected to exceed the tortuosity for the ash layer diffusivity, so that, in this one-dimensional model, the effective pore diffusivity is less than the ash layer diffusivity. The COMSOL Multiphysics ${ }^{\circledR}$ model is a two-dimensional model and thus does not need a separate value for the pore diffusivity.

The pore diffusion model generates the Thiele modulus, which is proportional to the square root of the chemical reaction rate divided by the diffusivity. ${ }^{13,14}$ The model equates concentrations and mass transfer rates across a front that divides the ash layer from the pore diffusion layer. In this manner, the effects of diffusion and reaction kinetics are combined without the need to explicitly specify a diffusion layer thickness; this thickness is derived as a function of the relative rates of diffusion and reaction.

Fig. 3 illustrates the modeling of the moisture adsorption process. As this figure shows, the model divides the oxide bed into three layers, a top layer (the ash layer) where the oxide has adsorbed moisture to a level that is in equilibrium with the ambient relative humidity, a middle layer (the pore diffusion layer) where the adsorption occurs, and a bottom layer where the moist air has not yet penetrated. Mass transfer across the top layer occurs by diffusion in the vertical direction. Since it is assumed that there is no further adsorption in this layer, the concentration gradient is linear. In the middle layer, the surface adsorption reaction and vertical and transverse diffusion occur simultaneously. The concentration gradient in this layer decreases with increasing distance from the top surface of the oxide bed. It is assumed that no adsorption or diffusion of moisture takes place in the bottom layer. The model assumes that the water vapor concentration at the top surface of the oxide bed equals the concentration at the ambient temperature and relative humidity and that both the concentration and the vertical concentration gradient are continuous across the interface between the top and middle layers, as shown at the right side of Fig. 3.

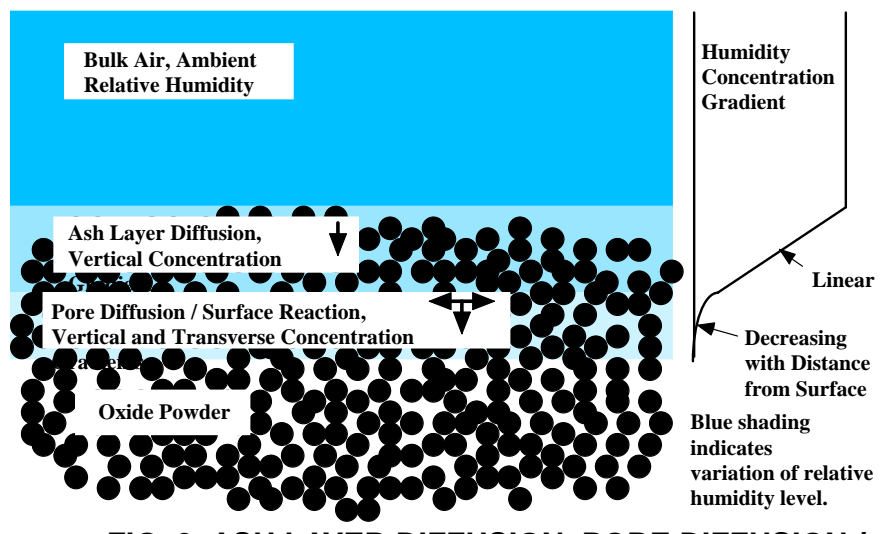

FIG. 3 ASH LAYER DIFFUSION, PORE DIFFUSION I SURFACE REACTION MOSITURE ADSORPTION MODEL

The rate of growth of the ash layer is related to the flux of water vapor entering the oxide powder by 


$$
(1-\varepsilon) \rho_{\mathrm{ox}} \mathrm{v}_{\mathrm{m}} \mathrm{N}_{\mathrm{s}} \mathrm{M}_{\mathrm{H}_{2} \mathrm{O}} \frac{\mathrm{dL}}{\mathrm{dt}}=-\mathrm{D}_{\mathrm{eff}} \rho_{\mathrm{g}, \mathrm{H}_{2} \mathrm{O}} \frac{\mathrm{dR}}{\mathrm{dx}}
$$

The pore diffusion model is applied by assuming that the rate of adsorption is sufficiently slow, and the amount of vapor contained in the pores is sufficiently small, that a quasi-steady state exists where the rate of mass influx by diffusion equals the intrinsic (chemical) rate of adsorption. As stated previously, the pore diffusion model is applied at some depth below the oxide surface; it is assumed that the oxide above this depth has adsorbed moisture nearly up to the saturation level. If the depth is defined as a distance $\mathrm{L}$ from the surface, then, for $\mathrm{x} \geq \mathrm{L}$,

$$
D_{\text {eff }} \rho_{g, H_{2} \mathrm{O}} \frac{d^{2} R}{d x^{2}}=k_{a} M_{H_{2} O}(1-\varepsilon) \rho_{o x} v_{m}
$$

The pore diffusion equation (Eq. 7) can be solved by a reduction of order. To reduce the order, the relative humidity gradient is specified as a dependent variable that is a function of the relative humidity. In terms of the relative humidity gradient,

$$
\mathrm{R}^{\prime}=\frac{\mathrm{dR}}{\mathrm{dx}}
$$

the pore diffusion equation can be written as

$$
D_{\text {eff }} \rho_{g, H_{2} \mathrm{O}} R^{\prime} \frac{d R^{\prime}}{d R}=k_{a} M_{H_{2} \mathrm{O}}(1-\varepsilon) \rho_{o x} v_{m}
$$

The initial condition for solving this equation is $R^{\prime}=0$ when $\mathrm{R}=0$. Eq. 9 is a quadratic equation with positive and negative roots. The viable solution for the specified diffusion direction is the negative root, which is given by

$$
\mathrm{R}^{\prime}=\frac{\mathrm{dR}}{\mathrm{dx}}=-\left(\frac{2 \mathrm{k}_{\mathrm{a}} \mathrm{M}_{\mathrm{H}_{2} \mathrm{O}}(1-\varepsilon) \rho_{\mathrm{ox}} \mathrm{v}_{\mathrm{m}} \mathrm{R}}{\mathrm{D}_{\text {eff }} \rho_{\mathrm{g}, \mathrm{H}_{2} \mathrm{O}}}\right)^{0.5}
$$

Eq. 10 gives the concentration gradient immediately below the diffusion front. The ash layer diffusion model is applied to the layer of oxide above the pore diffusion layer. For $\mathrm{x} \leq \mathrm{L}$, it is assumed that the entire oxide surface is in equilibrium with the water vapor and that no additional adsorption takes place. It follows that in the ash layer another quasi-steady state exists where

$$
\frac{\mathrm{dR}}{\mathrm{dx}}=-\left(\frac{\mathrm{R}_{0}-\mathrm{R}}{\mathrm{L}}\right)
$$

The pore diffusion and ash layer diffusion equations are combined to solve for the depth of the oxide layer that has adsorbed moisture. The equations are combined by setting the moisture concentration gradients equal at the interface where the two layers meet. Thus, at $\mathrm{x}=\mathrm{L}$,

$$
\frac{\mathrm{R}_{0}-\mathrm{R}}{\mathrm{L}}=\left(\frac{2 \mathrm{k}_{\mathrm{a}} \mathrm{M}_{\mathrm{H}_{2} \mathrm{O}}(1-\varepsilon) \rho_{\mathrm{ox}} \mathrm{v}_{\mathrm{m}} \mathrm{R}}{\mathrm{D}_{\mathrm{eff}} \rho_{\mathrm{g}, \mathrm{H}_{2} \mathrm{O}}}\right)^{0.5}
$$

Combination of Eqs. 10 and 12 gives, for the moisture gradient,

$$
\begin{aligned}
& \frac{\mathrm{dR}}{\mathrm{dx}}=-\left(\begin{array}{l}
\left(\frac{\mathrm{k}_{\mathrm{a}} \mathrm{M}_{\mathrm{H}_{2} \mathrm{O}}(1-\varepsilon) \rho_{\mathrm{ox}} \mathrm{v}_{\mathrm{m}} \mathrm{L}}{\mathrm{D}_{\text {eff }} \rho_{\mathrm{g}, \mathrm{H}_{2} \mathrm{O}}}\right)^{2} \\
+\frac{2 \mathrm{k}_{\mathrm{a}} \mathrm{M}_{\mathrm{H}_{2} \mathrm{O}}(1-\varepsilon) \rho_{\mathrm{ox}} \mathrm{v}_{\mathrm{m}} \mathrm{R}_{0}}{\mathrm{D}_{\text {eff }} \rho_{\mathrm{g}, \mathrm{H}_{2} \mathrm{O}}}
\end{array}\right)^{0.5} \\
& +\frac{\mathrm{k}_{\mathrm{a}} \mathrm{M}_{\mathrm{H}_{2} \mathrm{O}}(1-\varepsilon) \rho_{\mathrm{ox}} \mathrm{v}_{\mathrm{m}} \mathrm{L}}{\mathrm{D}_{\text {eff }} \rho_{\mathrm{g}, \mathrm{H}_{2} \mathrm{O}}}
\end{aligned}
$$

Substitution of Eq. 13 into Eq. 6 generates the equation for the rate of growth of the oxide layer with adsorbed moisture. This equation takes the form

$$
\begin{aligned}
& (1-\varepsilon) \rho_{\mathrm{ox}} \mathrm{v}_{\mathrm{m}} \mathrm{N}_{\mathrm{s}} \mathrm{M}_{\mathrm{H}_{2} \mathrm{O}} \frac{\mathrm{dL}}{\mathrm{dt}}= \\
& \left(\begin{array}{l}
\left(\mathrm{k}_{\mathrm{a}} \mathrm{M}_{\mathrm{H}_{2} \mathrm{O}}(1-\varepsilon) \rho_{\mathrm{ox}} \mathrm{v}_{\mathrm{m}} \mathrm{L}\right)^{2} \\
+2 \mathrm{k}_{\mathrm{a}} \mathrm{M}_{\mathrm{H}_{2} \mathrm{O}}(1-\varepsilon) \rho_{\mathrm{ox}} \mathrm{v}_{\mathrm{m}} \mathrm{D}_{\text {eff }} \rho_{\mathrm{g}, \mathrm{H}_{2} \mathrm{O}} \mathrm{R}_{0}
\end{array}\right)^{0.5} \\
& -\mathrm{k}_{\mathrm{a}} \mathrm{M}_{\mathrm{H}_{2} \mathrm{O}}(1-\varepsilon) \rho_{\mathrm{ox}} \mathrm{v}_{\mathrm{m}} \mathrm{L}
\end{aligned}
$$

It is convenient to use dimensionless variables to simplify this equation in order to facilitate its solution. Accordingly, a dimensionless oxide depth y and a dimensionless exposure time $\theta$ are defined as

$$
y=\left(\frac{k_{a} M_{\mathrm{H}_{2} \mathrm{O}}(1-\varepsilon) \rho_{\mathrm{ox}} \mathrm{v}_{\mathrm{m}}}{\mathrm{D}_{\mathrm{eff}} \rho_{\mathrm{g}, \mathrm{H}_{2} \mathrm{O}}}\right)^{0.5} \mathrm{~L}
$$

and

$$
\theta=\frac{\mathrm{k}_{\mathrm{a}} \mathrm{t}}{\mathrm{N}_{\mathrm{s}}}
$$

In terms of these dimensionless variables, Eq. 14 becomes

$$
\frac{\mathrm{dy}}{\mathrm{d} \theta}=\left(\mathrm{y}^{2}+2 \mathrm{R}_{0}\right)^{0.5}-\mathrm{y}
$$


Eq. 17 is integrated to obtain the depth of the adsorbed layer, starting with an initial depth of zero:

$$
\int_{0}^{\mathrm{y}} \frac{\mathrm{dy}}{\left(\mathrm{y}^{2}+2 \mathrm{R}_{0}\right)^{0.5}-\mathrm{y}}=\int_{0}^{\theta} \mathrm{d} \theta
$$

The integral solution is expressed as

$$
\begin{aligned}
& \frac{\mathrm{R}_{0}}{2\left(2 \mathrm{y}^{2}+2 \mathrm{R}_{0}-2 \mathrm{y}\left(\mathrm{y}^{2}+2 \mathrm{R}_{0}\right)^{0.5}\right)}-\frac{1}{4} \\
& -\frac{1}{4} \ln \left(\frac{2 \mathrm{y}^{2}+2 \mathrm{R}_{0}-2 \mathrm{y}\left(\mathrm{y}^{2}+2 \mathrm{R}_{0}\right)^{0.5}}{2 \mathrm{R}_{0}}\right)=\theta
\end{aligned}
$$

This solution is applicable up to the point where the oxide surface becomes saturated with adsorbed moisture.

\section{MODEL FOR EQUILIBRIUM ADSORPTION ISOTHERM}

Veirs, Berg, and Crowder measured and correlated the amount of moisture that is adsorbed onto plutonium dioxide powders. ${ }^{4}$ Their correlation is based on the Brunauer-EmmettTeller (BET) model, ${ }^{15}$ which commonly is used to obtain specific surface area measurements. ${ }^{16}$ The BET theory gives the number of monolayers of adsorbed moisture as a function of the relative humidity. The number of monolayers can be converted into the wt \% adsorbed moisture by multiplying by the adsorbed moisture content in a single monolayer:

$$
\mathrm{m}_{\mathrm{H}_{2} \mathrm{O}}=\mathrm{n}_{\mathrm{m}} \mathrm{w}_{\mathrm{H}_{2} \mathrm{O}}
$$

The BET model correlates the number of monolayers as a function of the relative humidity using an adsorption isotherm constant. The BET equation for the number of monolayers takes the form

$$
\mathrm{n}_{\mathrm{m}}=\frac{\mathrm{cR}}{(1-\mathrm{R})^{2}\left(1+\frac{\mathrm{cR}}{1-\mathrm{R}}\right)}
$$

The adsorption isotherm is related to the excess heat of adsorption (i.e., the heat of adsorption in excess of the normal heat of condensation for water vapor) by the relation

$$
c=\exp \left(\frac{\Delta \mathrm{H}_{\mathrm{ad}}}{\mathrm{R}_{\mathrm{g}} \mathrm{T}}\right)
$$

The excess heat of condensation is assumed to be independent of temperature.
Veirs, Berg, and Crowder correlated their adsorption data using an adsorption isotherm constant of 7 for measurements at a reference temperature of $23{ }^{\circ} \mathrm{C}(296.15 \mathrm{~K})$. Thus, as a best estimate,

$$
\mathrm{c}_{0}=\exp \left(\frac{\Delta \mathrm{H}_{\mathrm{ad}}}{\mathrm{R}_{\mathrm{g}} \mathrm{T}_{0}}\right)=7
$$

From equations 22 and 23,

$$
\ln (c)=\frac{T_{0}}{T} \ln (7)
$$

To convert the number of monolayers of moisture that is adsorbed to a mass fraction, the thickness of a monolayer of water must be estimated. The customary approach to calculating a monolayer thickness is to assume that the molecules of the adsorbed liquid are spherical and are arranged in the theoretical maximum density configuration, which a hexagonal close-packed structure. The surface area for one molecule of water in such close-packed layers is calculated by assigning the molecule the shape of a hexagonal disk, for which the thickness equals the average thickness of the close-packed layer and the distance between sides equals the diameter of the spherical molecule. The formula for the molecular area, in terms of Avogadro's number, the molecular weight of water, and the liquid water density, is

$$
\mathrm{A}_{\mathrm{H}_{2} \mathrm{O}}=12^{0.5}\left(\frac{\mathrm{M}_{\mathrm{H}_{2} \mathrm{O}}}{32^{0.5} \mathrm{~N}_{\mathrm{A}} \rho_{\mathrm{H}_{2} \mathrm{O}}}\right)^{2 / 3}
$$

From Eq. 25, the moisture content that corresponds to a single monolayer on the oxide surface is given by

$$
\mathrm{w}_{\mathrm{H}_{2} \mathrm{O}}=\frac{(1 \mathrm{E} 6) \mathrm{s}_{\mathrm{BET}}}{12^{0.5}\left(\frac{\mathrm{N}_{\mathrm{A}}}{32 \mathrm{M}_{\mathrm{H}_{2} \mathrm{O}} \rho_{\mathrm{H}_{2} \mathrm{O}}{ }^{2}}\right)^{1 / 3}}
$$

The preceding equations are solved to obtain either the number of monolayers or the wt \% of adsorbed moisture at equilibrium, if the temperature and the specific surface area of the oxide are known. Fig. 4 plots the number of monolayer of adsorbed moisture and the wt \% adsorbed moisture as functions of the relative humidity. The assumed temperature for Fig. 4 is the reference temperature of $296 \mathrm{~K}\left(23{ }^{\circ} \mathrm{C}\right)$, and the specific surface area for is $10 \mathrm{~m}^{2} / \mathrm{g}$. Calculations show that at $50 \%$ relative humidity, there are 1.75 monolayers of adsorbed moisture, or about $0.5 \mathrm{wt} \%$ adsorbed moisture, at equilibrium. It may be noted that this amount represents physisorbed moisture that adds to the amount of moisture that is chemisorbed. 
SRNL-STI-2013-00649

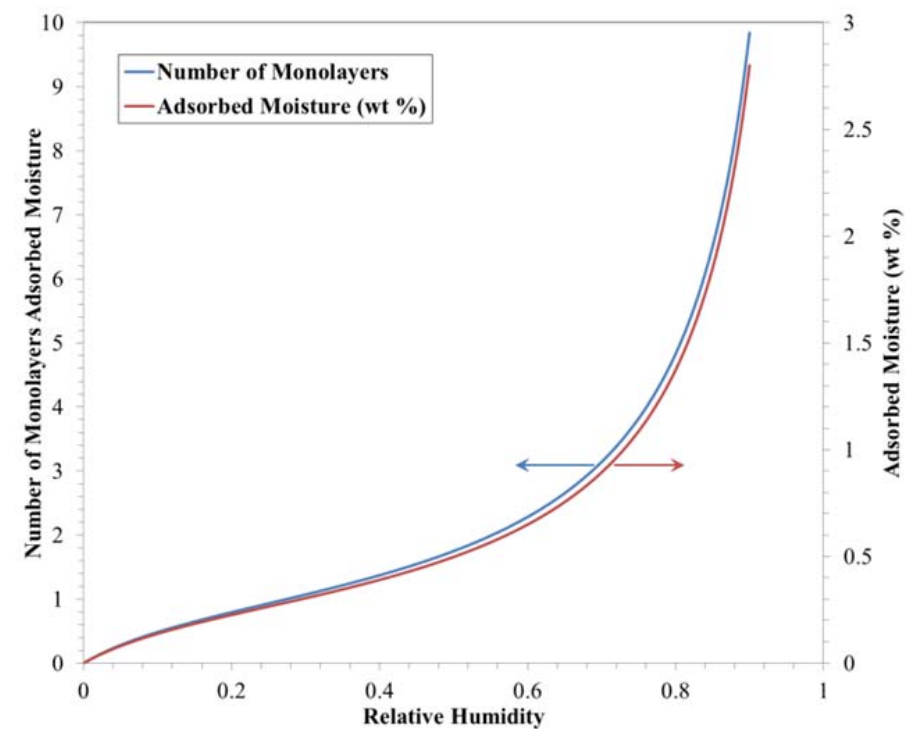

FIG. 4 MONOLAYERS AND WEIGHT FRACTION ADSORBED MOISTURE AS FUNCTIONS OF RELATIVE HUMIDITY

\section{BENCHMARKING OF ADSORPTION RATE MODELS}

As stated previously, an intrinsic chemical adsorption rate is calculated from Berg et al. data for moisture adsorption from humidified helium, ${ }^{1}$ and the diffusion-limited rate of adsorption is benchmarked against data obtained by Haschke and Ricketts. ${ }^{2,3}$ The Berg et al. measurements showed that, for adsorption of moisture onto a representative sample of plutonium oxide from humidified helium gas, the initial rate of adsorption, after an approximately one-minute long initiation interval, was nearly constant with respect to time. The measured data are used to compute the intrinsic adsorption rate. This use assumes that the large relative density difference between water vapor and helium negated the resistance to diffusion for this test, so that the measured rate represents a true intrinsic chemical adsorption rate. In this analysis, the rate is normalized with respect to the specific surface area of the oxide. The rate is based on a constant weight gain rate of $0.0449 \mathrm{wt} \% / \mathrm{min}$, for an oxide with a surface area of $18.1 \mathrm{~m}^{2} / \mathrm{g}$ (see the least squares date regression in Fig. 5). The normalized rate is $7.92 \mathrm{E}-05 \mathrm{~mol} / \mathrm{m}^{2} / \mathrm{h}$.

Both the COMSOL Multiphysics ${ }^{\circledR}$ model and the analytical ash layer/pore diffusion model are benchmarked against the Haschke and Ricketts data for oxide calcined at $700{ }^{\circ} \mathrm{C}$ using the tortuosity factor as the fitting parameter. For the analytical model, a fit to moisture adsorption data was obtained using a tortuosity factor of four for the pore diffusion and a tortuosity factor of two for the interparticle diffusion. The COMSOL Multiphysics ${ }^{\circledR}$ model was fit using a single value of three for the tortuosity.

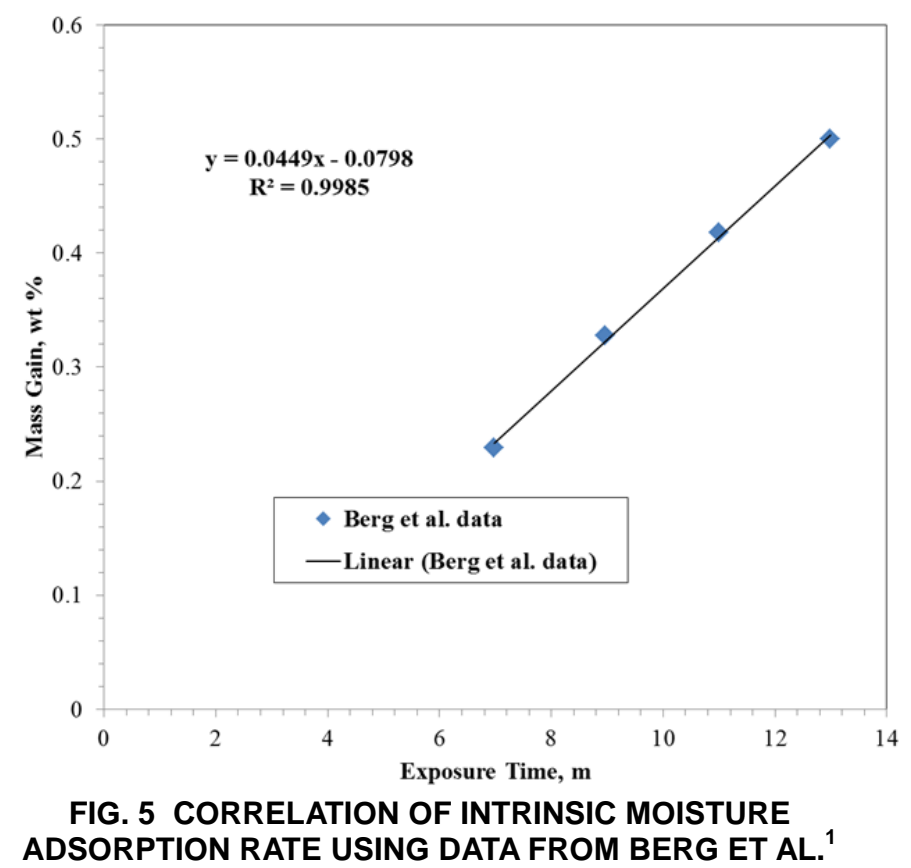

The interparticle tortuosity has been estimated as being equal to two ${ }^{17}$ or no higher than three, from a parallel capillary model. ${ }^{18}$ The pore diffusion tortuosity is somewhat higher than typically cited for interparticle diffusion but is representative of tortuosities measured for gas diffusion in soils, where there is significant liquid phase pore blockage. ${ }^{19}$ The tortuosity for the COMSOL Multiphysics ${ }^{\circledR}$ model is equal to the average of the two tortuosities used in the analytical model.

A separate finite element mesh with a constant crosssectional area and a depth equal to that for the Haschke and Ricketts test $(0.006 \mathrm{~m})$ was constructed for the COMSOL Multiphysics benchmarking calculations. The humidity at the top surface of the oxide layer was set equal to $1 \%$ as in the Haschke and Ricketts test.

Fig. 6 compares the analytical and COMSOL Multiphysics model calculations with the Haschke and Ricketts test data. Both models fit the data well over the initial portion of the adsorption transient. The analytical model deviates significantly from the data as the adsorbed moisture concentration approaches equilibrium. This deviation occurs because the analytical model does not include a defined oxide layer thickness but instead treats this layer as semi-infinite. In lieu of a defined thickness, equilibrium is forced into the analytical model by specifying a maximum moisture concentration equal to the maximum measured concentration.

An adsorption isotherm constant of 155 was used to fit the maximum adsorption concentration measured by Haschke and Ricketts. It is recognized that this constant is considerably larger than the value of 7 used to model the B vial adsorption transient. The use of a larger constant is justified by the fact that the Haschke and Ricketts material evidently was freshly calcined and consequently contained very little moisture at the start of the test. The value selected for the B vial calculations is 
based on recommendations from Veirs, Berg, and Crowder for typical oxide powders, and gives a better estimate of the average sensitivity of the adsorbed moisture concentration to changes over the entire range of relative humidity. ${ }^{3}$ Indeed, comparisons of adsorption isotherms for different isotherm constants show that the amount of adsorbed moisture is sensitive at low humidities (below about 20\% relative humidity), but much less sensitive at the higher humidities for the $\mathrm{B}$ vial calculations. ${ }^{4}$

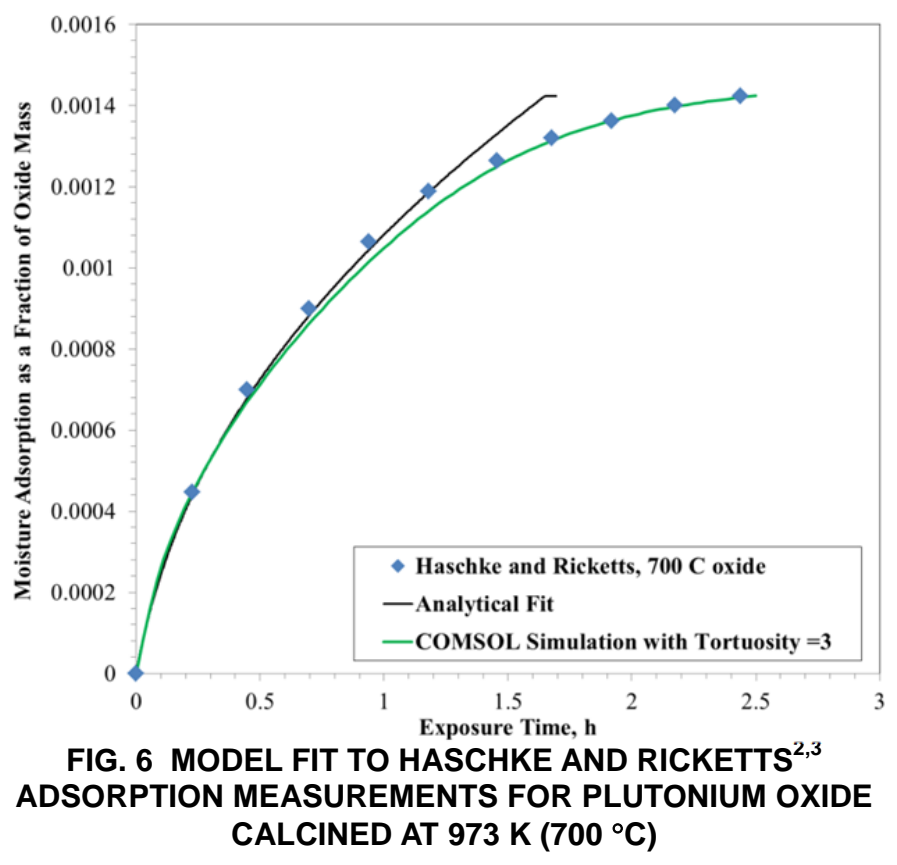

\section{PARAMETRIC ADSORPTION RATE ANALYSES}

The COMSOL Multiphysics ${ }^{\circledR}$ model was used to compute moisture adsorption transients for exposure of the oxide layer to air with 50\%, 60\%, and 70\% relative humidity. The oxide layer thickness in the B vial was computed from an assumed bulk density of $1800 \mathrm{~kg} / \mathrm{m}^{3}$ and a mass of $0.004 \mathrm{~kg}$. The initial conditions for the calculations were an adsorbed moisture content of zero and zero relative humidity in the air inside the oxide powder layer. Initially, the humidity of the air in the vial gas space above the oxide layer was set equal to the ambient relative humidity. The ambient air was kept at the specified relative humidity (either $50 \%, 60 \%$, or $70 \%$ ) for the duration of the transient.

Three cases are analyzed, a worst case (maximum rate of adsorption) in which the gas space above the oxide layer was assumed to be mixed with the ambient air all the way down to the oxide layer surface, a best case (minimum rate of adsorption) in which the gas space was assumed not to mix, and an intermediate case in which the gas space was assumed to mix down to one gap width $(0.0137 \mathrm{~m})$ below the vial top for flow across the top. Fig. 7 compares the average relative humidity transients for these three cases when the ambient relative humidity is set at $50 \%$. The adsorbed water in this figure represents the average moisture content of the oxide for an ambient relative humidity of $50 \%$. It is apparent that mixing between the ambient air and the gas initially in the vial significantly influences the rate of adsorption. As shown in Fig. 7 , the average adsorbed water content reaches half its equilibrium value of $0.5 \mathrm{wt} \%$ approximately $10 \mathrm{~min}, 1 \mathrm{~h}$, and $2 \mathrm{~h}$ exposure to moist air for the worst case, intermediate case, and best case mixing, respectively.

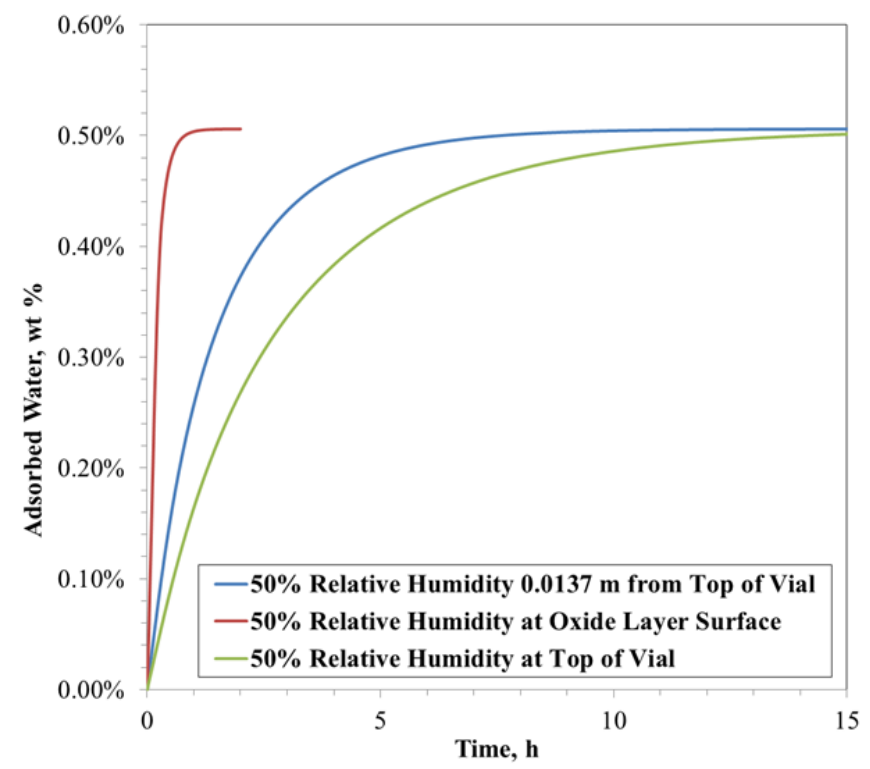

FIG. 7 EFFECT OF MIXING ABOVE THE OXIDE LAYER IN THE B VIAL ON THE AVERAGE ADSORBED MOISTURE CONTENT

Fig. 8 plots the average oxide moisture transients for $50 \%$, $60 \%$, and $70 \%$ ambient relative humidities, for the case where gas mixing occurs $0.0137 \mathrm{~m}$ below the top of the vial. The adsorption isotherm yields maximum moisture contents of 0.50 wt $\%$ at $50 \%$ relative humidity, 0.65 wt $\%$ at $60 \%$ relative humidity, and $0.92 \mathrm{wt} \%$ at $70 \%$ relative humidity. The adsorption rates shown in these figures initially are linear, indicating that the rate is limited to the intrinsic rate of chemisorption or physisorption at the oxide particle surfaces. Later in the transients, the rates decrease with time, indicating that gas diffusion is a limiting factor. Finally, the rates level off to equilibrium, as the oxide particle surfaces become saturated with moisture at the ambient relative humidity. It is noteworthy that the adsorption transient is linear for a significant time when the gas above the oxide layer is completely mixed. This signifies that the diffusion within the oxide layer itself does not limit the overall adsorption rate to a large extent.

Fig. 9 compares adsorption rates in a product can containing oxide with a density of $1500 \mathrm{~kg} / \mathrm{m}^{3}$, when gas mixing is assumed to occur at the top of the can. Initial adsorption rates are higher for the 1.2-kg oxide layer because the oxide surface is closer to the top of the can, thus increasing the diffusion rate in the gas layer above oxide. Later in the transient, the rates for the 0.65-kg layer are higher. The faster 
adsorption rates can be attributed partly to the shorter diffusion path through the $0.65-\mathrm{kg}$ layer and partly to the heating of the oxide by moisture condensation and adsorption. Due to heat transfer limitations, the 1.2-kg layer will become hotter than the $0.65-\mathrm{kg}$ layer as adsorption proceeds. Because the adsorption capacity of the oxide decreases as the temperature increases (see Eq. 24), this temperature difference results in less moisture being adsorbed in the 1.2-kg layer.

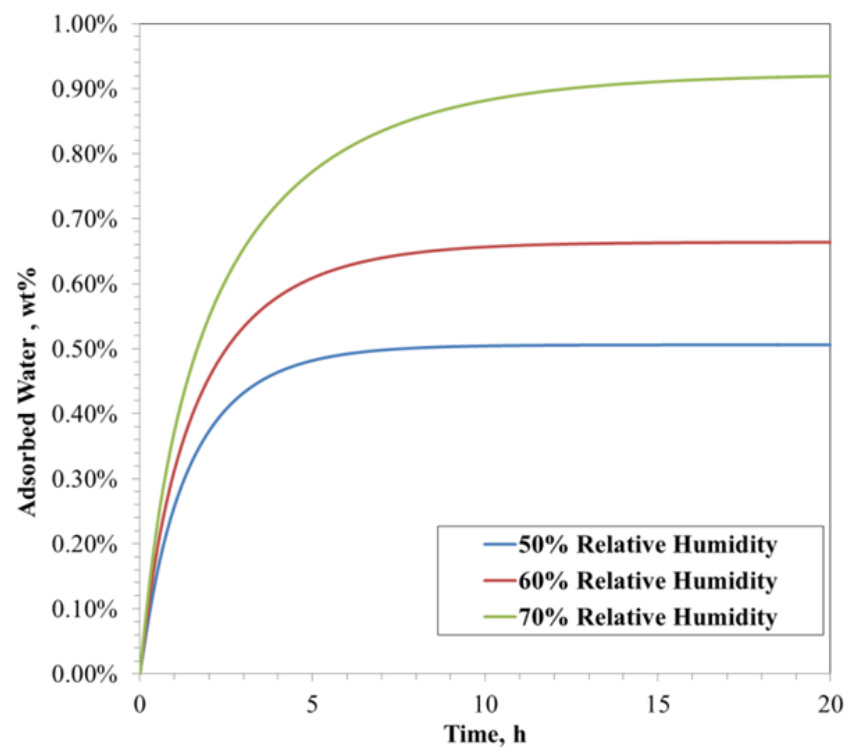

FIG. 8 EFFECT OF RELATIVE HUMIDITY ON AVERAGE ADSORBED MOISTURE CONTENT FOR DIFFUSION OF WATER VAPOR 0.0137 M FROM THE TOP OF THE B VIAL

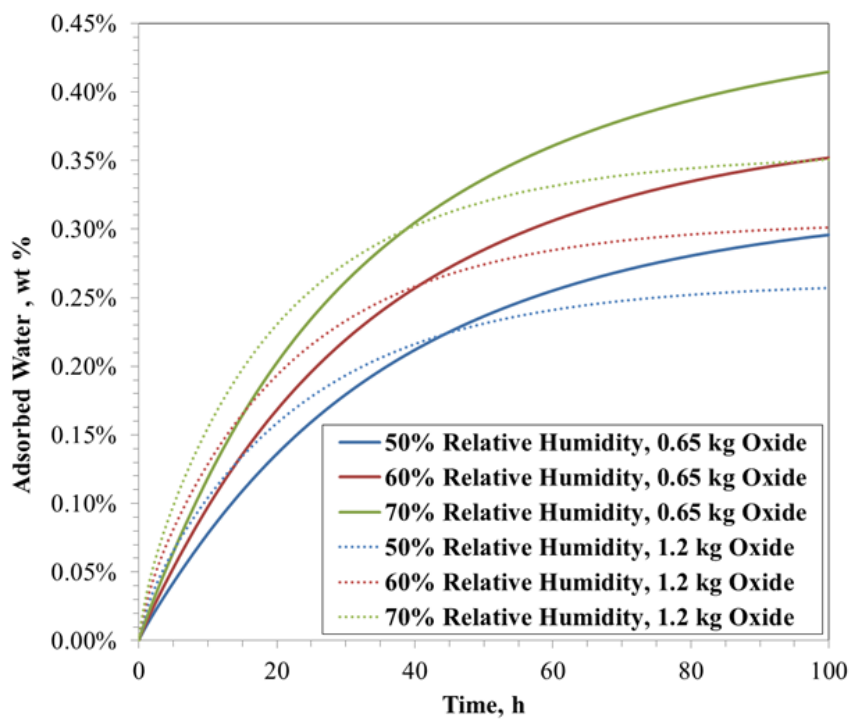

FIG. 9 EFFECTS OF RELATIVE HUMIDITY AND OXIDE LAYER THICKNESS ON AVERAGE ADSORBED MOISTURE CONTENT IN THE PRODUCT CAN

Figs. 10 and 11 depict typical moisture concentration profiles in the B vial and the product can. As Fig. 10 shows, the moisture level in the $\mathrm{B}$ vial is nearly uniform at a given level, with a slight variation due to the decrease in the oxide layer area at the bottom of the vial. In the product can, as may be seen in Fig. 11, moisture concentrations are significantly higher at the top and bottom and along the outside wall than in the center of the oxide layer. The concentration variations are due to the temperature gradients inside the oxide layer, which cause the moisture saturation concentrations to be higher along the cooler edges of the layer than in the hotter center.

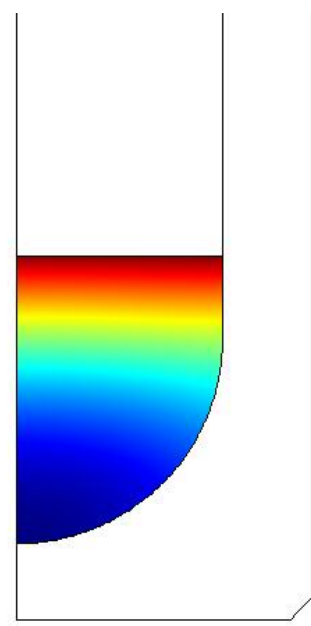

187.39

185

180

175

170

165

160

155

150

145

140

135

132.68

FIG. 10 ADSORBED MOISTURE CONCENTRATIONS AFTER 30 MIN FOR DIFFUSION OF WATER VAPOR FROM $50 \%$ RELATIVE HUMIDITY AIR 0.0137 M FROM THE TOP OF THE $B$ VIAL (Concentration in $\mathrm{mol} / \mathrm{m}^{3}$ is listed on color scale.)

$\Delta 382.64$

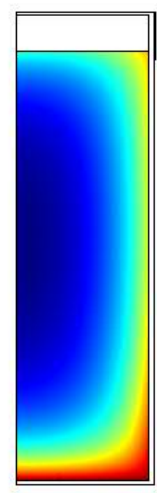

350

300

250

200

150

140.24

FIG. 11 ADSORBED MOISTURE CONCENTRATIONS IN 1.2-KG OXIDE LAYER AFTER 50 H FOR WATER VAPOR DIFFUSION FROM 50\% RELATIVE HUMIDITY AIR AT THE TOP OF THE PRODUCT CAN (Concentration in $\mathrm{mol} / \mathrm{m}^{3}$ is listed on color scale.) 


\section{SUMMARY AND CONCLUSIONS}

A COMSOL Multiphysics ${ }^{\circledR}$ finite element model has been developed to predict the rate of moisture adsorption into plutonium oxide powders exposed to ambient air. The model incorporates equilibrium moisture adsorption isotherms into a transient water vapor diffusion and heat transfer analysis. The adsorption isotherms and powder layer thermal conductivity used by the model were obtained from LANL studies. ${ }^{4,8}$ The diffusion calculations are based on an effective water vapor diffusivity in the oxide layer. An effective diffusivity with a tortuosity factor of 3 was used to successfully benchmark the finite element mass transfer model with plutonium oxide moisture adsorption tests conducted by Haschke and Ricketts. ${ }^{2,3}$ The Haschke and Ricketts tests also are successfully benchmarked using a simplified analytical, one-dimensional ash and pore diffusion analysis.

The $\mathrm{COMSOL}^{\circledR}$ model is used to predict the rate of moisture adsorption into plutonium oxide powders stored in open containers. Parametric calculations predict rates of adsorption into oxide layers inside small $\mathrm{B}$ vials and larger product cans currently being used at SRS. Adsorption rates are calculated for different oxide layer thicknesses, ambient relative humidities and mixing conditions in the gas above oxide layer.

It is anticipated that the model will be used to determine the effect of processing times, i.e., the duration of exposure to ambient air, on the moisture content of plutonium oxide powders. It is expected that the model also will find use in determining acceptable techniques for obtaining representative samples for moisture analysis. Notably, results indicate that there will be significant moisture gradients for oxide powders stored in the SRS product cans.

\section{REFERENCES}

1. Berg, J.M., Narlesky, J.E., and Veirs, D.K., “A Summary of Volatile Impurity Measurements and Gas Generation Studies on MISSTD-1, a High-Purity Plutonium Oxide Produced by Low-Temperature Calcination of Plutonium Oxalate,” LANL Report LA-UR-12-21473, 2012.

2. Haschke, J.M., and Ricketts,T.E., "Plutonium Dioxide Storage: Conditions for Preparation and Handling,” LANL Report LA-12999-MS, 1995.

3. Haschke, J.M., and Ricketts, T.E., "Adsorption of Water on Plutonium Dioxide,” J. Alloys Compd., 252, 148-156, 1997.

4. Veirs, D.K., Berg, J.M., and Crowder, M.L., "The Effect of Plutonium Dioxide Water Surface Coverage on the Generation of Hydrogen and Oxygen,” LANL Report LA-UR-12-22377, 2012.
5. Incropera, F.P., and DeWitt, D.P., Fundamentals of Heat and Mass Transfer, $4^{\text {th }}$ ed., John Wiley \& Sons, New York (1996), p. 509.

6. Saidi, C., Legay-Desesquelles, F., and Prunet-Foch. B., "Laminar Flow Past a Sinusoidal Cavity," Int. J. Heat Mass Transfer, 30(4), 649-661, 1987.

7. Sinha, S.N., Gupta, A.K., and Oberai, M.M., "Laminar Separating Flow over Backsteps and Cavities, Part II: Cavities,” AIAA J., 20(3), 370-375, 1982.

8. Bielenberg, P.A., Prenger, F.C., Veirs, D.K., and Jones, G.F., "Effects of Pressure on Thermal Transport in Plutonium Oxide Powder,” Int. J. Heat Mass Transfer, 49, 3229-3239, 2006.

9. Dortmund Data Bank Software and Separation Technology GmbH (www.ddbst.com).

10. Perry's Chemical Engineers' Handbook, $6^{\text {th }}$ ed., McGrawHill, New York (1984), p. 3-285.

11. Levenspiel, O., Chemical Reaction Engineering, $3^{\text {rd }}$ ed., John Wiley \& Sons, New York (1999), pp. 573-576.

12. Levenspiel, O., Chemical Reaction Engineering, $3^{\text {rd }}$ ed., John Wiley \& Sons, New York (1999), pp. 381-391.

13. Thiele, E.W., "Relation between Catalytic Activity and Size of Particle,” Ind. Eng. Chem., 31(7), 916-920, 1939.

14. Froment, G.F., and Bischoff, K.B., "Kinetic Data and Product Distributions from Fixed Bed Catalytic Reactors Subject to Catalyst Fouling,” Chem. Eng. Sci., 17, 105114, 1962.

15. Brunauer, S., Emmett, P.H., and Teller, E., “Adsorption of Gases in Multimolecular Layers,” J. Am. Chem. Soc., 60(2), 309-319, 1938.

16. Webb, P.A., and Orr, C., Analytical Methods in Fine Particle Technology, Micrometrics Instrument Corporation, Norcross, Georgia (1997), p. 61.

17. Epstein, N., "On Tortuosity and the Tortuosity Factor in Flow and Diffusion through Porous Media," Chem. Eng. Sci., 44(3), 777-779, 1989.

18. Dullien, F.A.L., Porous Media: Fluid Transport and Pore Structure, Academic Press, New York (1979).

19. Chamindu Deepagoda, T.K.K., Moldrup, P., Schjonning, P., Kawamoto, K., Komatsu, T., and de Jonge, L.W., "Variable Pore Connectivity Model Linking Gas Diffusivity and Air-Phase Tortuosity to Soil Matric Potential,” Vadose Zone J., 11, 10, 2012. 